\title{
BREVE INVESTIGAÇÃO GENEALÓGICA SOBRE O OUTRO*
}

\author{
NADJA HERMANN ${ }^{* *}$ \\ Como por descuido se dá um \\ desvelamento, atrás do outro... \\ (Oitava elegia, Rainer Maria Rilke)
}

\begin{abstract}
RESUMO: O artigo investiga o movimento constitutivo dos modos de relação que a subjetividade estabelece com o estranho e o outro. Num primeiro momento, destaca-se a constituição de uma relação de identidade e exclusão que remonta ao início da Filosofia, com a teoria platônica, na qual o estranho se situa no corpo e no afastamento penoso das pulsões e dos afetos, pela separação entre corpo e alma. Num segundo momento, retoma-se, a partir de Hegel, o movimento da subjetividade como autoconsciência e sua relação com o estranho ou a alteridade, na luta pelo reconhecimento. Outra possibilidade apresenta-se com a hermenêutica filosófica de Gadamer, cujo giro em direção à conversação não retrocede à dialética platônica nem à hegeliana, mas significa um movimento de saída de si mesmo, "pensar com o outro e voltar sobre si mesmo como outro". Pretende-se mostrar também os limites, as possibilidades e as ambivalências de nossa compreensão do outro.
\end{abstract}

Palavras-chave: O outro. O estranho. Subjetividade. Hermenêutica filosófica.

\section{A BRIEF GENEALOGICAL INVESTIGATION ON THE OTHER}

ABSTRACT: This paper investigates the constitutive movement of the types of relationships subjectivity maintains with the strange and the other. It first highlights the constitution of a relationship of identity and exclusion that dates back to the origins of philosophy with Plato's theory, in which the strange is located in the body and in painful detachment from drives and affects, through the separation of body and soul. Then, based on Hegel's perspective, it considers subjectivity as self-consciousness and its relationship with the strange or alterity in search of recognition. Another possibility emerges from Gadamer's philosophical hermeneutics, which dialogue does not relate to Plato's or Hegel's dialectics but to a movement out of oneself,

* $\quad$ Este trabalho faz parte da pesquisa "Ética e educação: a questão do outro", financiada pelo cNPq, por meio de Bolsa de Produtividade em Pesquisa.

** Doutora em Educação e professora de Filosofia da Educação no Programa de Pós-Graduação em Educação, Pontifícia Universidade Católica do Rio Grande do Sul (PUCRs). E-mail: nadja.hermann@ pucrs.br 
"thinking with the other and returning to oneself as other". It also aims to show the possibilities and ambivalence of our comprehension of the other.

Key words: The other. The strange. Subjectivity. Philosophical hermeneutics.

\section{BRÈVE RECHERCHE GÉNÉALOGIQUE SUR L'AUTRE}

RÉSUMÉ: Cet article examine le mouvement constitutif des modes de relation que la subjectivité établit avec l'étranger et l'autre. Dans un premier moment, il distingue la constitution d'une relation d'identité et d'exclusion remontant au début de la philosophie, avec la théorie platonique, dans laquelle l'étranger se situe dans le corps et dans l'éloignement pénible des pulsions et affects, par la séparation entre corps et âme. Dans un second moment, il reprend, à partir de Hegel, le mouvement de la subjectivité en tant que conscience de soi et son rapport à l'étranger ou l'altérité, dans la lutte pour la reconnaissance. Une autre possibilité se dessine avec l'herméneutique philosophique de Gadamer, dont le retour à la conversation ne rétrocède pas à la dialectique platonique ni hégélienne, mais signifie un mouvement de sortie de soi-même, "penser avec l'autre et revenir sur soi-même comme autre". Il prétend également montrer les limites, les possibilités et les ambivalences de notre compréhension de l'autre.

Mots-clefs: L’autre. L'étranger. Subjectivité. Herméneutique philosophique.

$\mathrm{A}$

questão do outro não tem o mesmo peso filosófico que a pergunta pelas causas do mundo, pela alma, pela justiça e tampouco é uma tematização específica na tradição do pensamento filosófico até o medievo. Sua abordagem mais explícita encontra-se, sobretudo, no pensamento moderno, a partir do princípio da subjetividade e do consequente modo como o sujeito se relaciona com o outro, com o estranho. O emprego da palavra "outro" aparece associado ao estranho da identidade, a tudo que lhe é contrário, distinto e inverso. Como lembra Ricoeur (1996), a filosofia do sujeito é paradigmática, pois, na medida em que o "eu penso" funda todas as relações, o eu expressa-se sem a confrontação de algo fora de si mesmo e isso configura uma espécie de prólogo a tal tema. Como ter acesso ao outro? Ele é apenas minha representação? O outro é aquilo que é estranho ao eu? Eles são excludentes ou complementares? Como se situa a questão do outro numa perspectiva ética?

O eu, que não depende de nenhuma alteridade, forma uma espécie de condição "pré-cognitiva a priori" sob a qual o outro se torna disponível, gerando um espectro de significados que se associam e se interconectam: eu e identidade, o outro e o estranho, a radical estranheza da identidade e a alteridade. Daí decorre um conjunto de conceitos e relações, cujos primeiros esboços e discussões teóricas se encontram na filosofia antiga.

O presente artigo pretende indicar alguns pontos relevantes do movimento constitutivo do conceito de outro e suas relações, uma genealogia que exponha sua historicidade, com vistas a compreender as razões que criaram as dificuldades de 
relação com o outro, com aquilo que foi sendo sistematicamente excluído ou não percebido pelos nossos esquemas interpretativos. O procedimento genealógico permite reconhecer aqueles elementos que mantiveram sua força de afecção, que produziram efeito a ponto de que a criação de categorias conceituais sobre o outro ou o refinamento das existentes, de algum modo, remetam a esse movimento, seja na perspectiva de afirmá-lo, negá-lo ou recriá-lo inteiramente.

Num primeiro momento, pode-se reconhecer um modo de relação caracterizado pelo binômio identidade como transparência e outro como exclusão. ${ }^{1}$ Tal modo de relação remonta ao início da Filosofia, com a teoria platônica, na qual o estranho ou o outro se situa no corpo e no afastamento penoso das pulsões e dos afetos.

Nessa concepção de natureza humana, o corpo é o outro da alma e tende a se tornar estranho à própria identidade de si. A alma é um princípio incessante de vida inteligente, um princípio vital, "é mais afim que o corpo ao invisível e este o é ao visível" (Platão, 1986, v. 3, p. 70). O corpo percebe a multiplicidade, a pluralidade da realidade, aquilo que é visível e as coisas "que se mantêm idênticas não é possível captálas jamais com outro meio, senão com o raciocínio da inteligência" (idem, ibid., p. 69). A alma mantém a identidade consigo mesma, pela sua ação racional, ao passo que o corpo, provocado pela multiplicidade sensível, impulsiona-se para o distanciamento da unidade. Essa interpretação aparece no Fédon e revela a influência que Platão recebe da concepção mágico-religiosa de psyché, cujo puritanismo-dualista atribui ao corpo mortal as causas do pecado e do sofrimento da alma ${ }^{2}$ (cf. Dodds, 1978, p. 212). O corpo cria dificuldades para a alma alcançar o bem, desvia-a. Então, como Platão assume em sua formulação considerada clássica (idem, ibid.), só pela morte ou pelo autodomínio do eu racional a alma será purificada da "insensatez do corpo" (Platão, op. cit., p. 45) e terá acesso à verdade e ao bem. A "ordem" e a "retidão" (Platão, 1983, v. 2, p. 116) conduzem à unidade e à identidade e aquilo que a isso escapa, especialmente as afecções provocadas pelo corpo, avança para a estranheza.

Wils lembra apropriadamente que esse movimento - a eliminação do estranho para manter a identidade - produz uma "exclusão trágica", que reaparece na pergunta do diálogo Parmênides: “(...) mas se alguém demonstra que eu sou um e múltiplo, por que isso haveria de nos surpreender?" (Platão, 1998, v. 5, p. 40). Ou seja, essa pergunta dá indícios da problematização do outro, sugere que pode haver no eu a identidade e o estranho, mas tal reconhecimento ou abertura é obstaculizada por uma estrutura de pensamento que tende à unidade e à finalidade.

Se a questão não é respondida na teoria platônica, uma afirmação semelhante àquilo que contém na pergunta do Parmênides é feita por Rimbaud em duas cartas, em 1871, onde o poeta afirma: "Eu é um outro" (je suis an outre). ${ }^{3}$ Dizer que eu é um outro é diferente de dizer que há outro e a agudeza de tal afirmação consiste em reconhecer que não somos unidade, mas constituídos por partes contraditórias. $\mathrm{O}$ 
tema, retomado no século xIX, sob profundas mudanças espirituais e culturais que se traduzem em novas experiências de si, mostra o eu em seu caráter múltiplo, fragmentário, numa espécie de antítese a tudo o que vinha sendo conjurado como identidade. Há algo que escapa, projeta o eu em algo indecidível, fratura a identidade e traz a existência do outro, seja no plano do corpóreo, das ações, do imaginativo ou daquilo que amedronta. $\mathrm{O}$ outro aponta o estranho, aquilo que ultrapassa a intimidade do eu, algo que precisou de muitos séculos depois do nascimento da Filosofia na Grécia, para irromper como um relato de experiência poética, expondo o deslocamento de uma concepção metafísica da identidade para uma concepção enraizada nos contextos plurais do mundo da vida, que se vê diante da alteridade, num eu que é atravessado pelo outro.

Embora sejam notórias as muitas interpretações da teoria de Platão, associadas à natureza dos diálogos que não são conclusivos e prescritivos, antes disso, são aporéticos, há certo acordo quanto à sua desconfiança do mundo empírico e da força poderosa do desejo, do corpóreo, da sedução que teve relevância para configurar o pensamento da identidade. Segundo Williams, Platão tem sempre presente que a mente humana é hostil ao bem, e não há nada que faça as pessoas buscarem a justiça "exceto sua própria compreensão filosófica da justiça e do bem. Elas [as pessoas] serão capazes de fazer isso desde que sua educação lhes dê uma compreensão filosófica do bem e do por que a justiça representa o desenvolvimento correto da alma racional" (Williams, 2000, p. 39). Nessa retidão e correção, ao encargo da alma racional, abre-se espaço para o idealismo, que, de acordo com Williams (op. cit., p. 61) dá sentido ao alerta de Nietzsche. Como se sabe, Nietzsche é crítico contumaz de Platão, trazendo com ironia perspectivas que não estavam tão evidentes. Seu alerta, no aforismo 372 de A gaia ciência (Die fröhliche Wissenschaft), expõe o que o idealismo dissimula:

(...) todo o idealismo filosófico foi, até agora, algo como uma doença, quando não foi, como no caso de Platão, a cautela de uma saúde muito rica e perigosa, o temor ante sentidos muito poderosos, a prudência de um prudente socrático. - Talvez nós, modernos, não sejamos saudáveis o bastante para necessitar do idealismo de Platão? (apud Nietzsche, v. 3, 1988, p. 624)

De algum modo, o idealismo preparou nosso olhar para reconhecer o idêntico, o mesmo. A dificuldade de lidar com o outro e, muitas vezes, seu aniquilamento, trouxe uma espécie de adoecimento, com desastrosas consequências para o plano político-cultural e ético. No plano político-cultural podem-se destacar as marcas deixadas pelo processo de colonização, que se deu sob violenta dominação das outras culturas, numa sistemática ausência de reconhecimento da diferença e com o predomínio de uma racionalidade técnico-científico e da superioridade intelectual dos colonizadores. Isso resultou numa desvalorização das culturas e, em termos mais recentes, da própria natureza, como o outro que foi violado. Com facilidade, aquilo que escapa ao que se entende como racional desliza para o bárbaro. 
A ética por sua vez enfrentou problemas quanto aos conteúdos reprimidos ou inexplorados pela visão metafísica, deparando-se com elementos poderosos que não eram abrangidos pela sua justificação. Pode-se lembrar a teoria de Kant que entende por moral o respeito a todos e a seus interesses de forma equitativa e, contudo, resulta numa formulação "estreita demais para que se possam incluir todos os aspectos que constituem o objetivo de um reconhecimento [do outro] não distorcido e ilimitado" (Honneth, 2003a, p. 269). Isso provocou uma série de novas tentativas de compreender o agir ético, que considere o outro e a intersubjetividade. Deve-se lembrar ainda, conforme analisa Waldenfels (1998, p. 88), que houve tentativas de relativizar o estranho, mas "esta duvidosa superação do estranho resulta humanisticamente dissimulada na conhecida frase de Terêncio: nihil humanum mihi alienum puto". ${ }^{4}$

Merece destaque, como momento significativo da relação do sujeito com o outro, a ideia de reconhecimento presente na filosofia de Hegel. No século XIX, o filósofo faz desse tema a questão central de toda ética, na medida em que a consciência de si depende da experiência de reconhecimento social, ou seja, o movimento da subjetividade, como autoconsciência, produz-se na relação com o outro, na luta pelo reconhecimento. Isso é relatado na Fenomenologia do espírito ${ }^{5}$ (1807), na qual figuras metafóricas dramatizam a constituição da consciência. $\mathrm{O}$ empenho hegeliano consiste em pensar a subjetividade na relação com o outro, com o que está fora da consciência.

Na primeira parte do capítulo Iv dessa obra, na conhecida dialética do senhor e do escravo, Hegel (2003, p. 142) afirma: "A consciência-de-si é em-si e para-si quando e porque é em si e para si para uma Outra; quer dizer, só é como algo reconhecido". Por meio da relação entre senhor e escravo, Hegel mostra o movimento de reconhecimento na relação social. Ambos necessitam um do outro para serem reconhecidos. Primeiramente, a consciência de si exclui todo o outro. O eu e o outro são figuras independentes, não se "apresentaram uma para a outra". Trata-se do momento em que o senhor impõe seu domínio e ainda não é reconhecido pelo escravo. Ambos, senhor e escravo, terão de submeter-se um ao outro por meio de uma luta de vida e morte, isto é, colocar-se em situação de risco, expor-se à consciência do outro, perder-se. Diz Hegel (op. cit., p. 146): “O indivíduo que não arriscou a vida pode bem ser reconhecido como pessoa, mas não alcançou a verdade desse reconhecimento como uma consciência-de-si independente". O senhor aprende que seu próprio domínio depende de ser reconhecido pelo escravo; ou seja, para uma consciência de si há outra consciência fora de si. Aqui o senhor depende do outro e é por ele mediatizado, no caso, o escravo, pois "a verdade da consciência independente é, por conseguinte, a consciência escra$v a^{\prime \prime}$ (idem, ibid., p. 149). Ao experimentar essa mediação, o senhor acaba dependente do escravo. E o escravo experimenta a angústia da dominação do senhor, o medo da morte: "Aí [a consciência] se dissolveu interiormente; em si mesma tremeu em sua totalidade; e tudo o que havia de fixo, nela vacilou" (idem, ibid.). A manutenção do 
domínio passa pela relação de dependência e o reconhecimento necessita de um outro, de outra consciência. O movimento dessas duas consciências é um agir de duplo sentido, não é só um "agir sobre si mesmo" e "sobre o Outro", mas é o agir "tanto de um quanto de Outro" (idem, ibid., p. 144). Pela mediação estabelece-se o reconhecimento; portanto, a consciência de si surge de uma complexa relação social.

O movimento descrito por Hegel indica o retorno da consciência sobre si, um si mesmo que não deve ser abandonado, pois "o eu é o conteúdo da relação e a relação mesma; defronta um Outro e ao mesmo tempo o ultrapassa; e este Outro, para ele, é apenas ele próprio" (idem, ibid., p. 135). Nessa relação descrita na Fenomenologia, o reconhecimento afirma o eu e o outro aparece como antagonismo:

A consciência-de-si é a reflexão, a partir do ser do mundo sensível e percebido; é essencialmente o retorno a partir do ser-Outro. Como consciência-de-si é movimento, mas, quando diferencia de si apenas a si mesma enquanto si mesma, então para ela a diferença é imediatamente suprassumida, como um ser-Outro. A diferença não é e a consciência-de-si é apenas a tautologia sem movimento do "Eu sou eu". (Hegel, 2003, p. 136)

Embora a dialética do senhor e do escravo tenha sido proposta como um modelo de reconhecimento do outro, a autoconsciência não é transparente como parece à primeira vista, pois ela vive de uma superação do outro e do estranho que recai numa irresistível negação. A solução é a superação do outro no universal. Como alerta Honneth (2003b, p. 473), só o interesse contemporâneo pelo reconhecimento, instigado pelo feminismo, multiculturalismo e pela teoria política, mostrará "a quantidade de problemas que tal perspectiva [a hegeliana] levanta". Em grande parte, o problema concentra-se na estrutura dialética, pela qual a existência do outro estaria relacionada apenas com o movimento da consciência para reconhecer a si mesma, o que resultaria num processo de aniquilamento do outro ou, pelo menos, de assimilação do outro a partir de nossos esquemas conceituais. Estaríamos assim diante da seguinte questão: mesmo para Hegel, em que a consciência de si resulta de um processo de reconhecimento do outro - movimento demonstrado na figura do senhor e do escravo -, estabelece-se a situação paradoxal de que o outro só existe para que o próprio sujeito possa se reconhecer. A alteridade seria, então, o meio necessário (como negatividade) ao reconhecimento do próprio sujeito como consciência de si. O outro, a diferença e a particularidade são concebidos como totalização, ou seja, momentos do universal.

É nessa perspectiva que Adorno critica Hegel: “com certeza, [Hegel] não podia admitir o não-verdadeiro da compulsão à identidade", pois a "negação da negação seria uma vez mais identidade, ofuscação renovada; projeção da lógica dedutiva e, por fim, do princípio da subjetividade" (Adorno, 1998, v. 6, p. 162). A negatividade passa a não mais surpreender e surge o embrutecimento da sensibilidade para aquilo que é não-idêntico. 
Na Teoria estética, Adorno (1998, v. 7, p. 273) indica o impasse da razão quando elimina de si mesma seu outro: “o que os indivíduos manipulados repelem lhes é apenas demasiado compreensível; analogamente à afirmação de Freud segundo a qual o estranho é estranho como aquilo que é intimamente demasiado familiar. Eis por que é repelido". No ensaio O estranho, de 1919, ao qual Adorno se refere, Freud relaciona o estranho (unheimlich) não apenas "com que é assustador - com o que provoca medo e horror" (1988, p. 237); mas "ao que é conhecido, de velho, e há muito familiar" (ibid., p. 238). Por meio de um detalhado levantamento do significado da palavra heimlich (familiar), Freud destaca seu caráter ambivalente "até que finalmente coincide com seu oposto" (ibid., p. 244). A categoria do estranho indica uma fratura do eu, que se situa no limite daquilo que é familiar e que deve ser dominado. O outro e o estranho não são apenas o externo à subjetividade, mas estão no interior do eu e, nessa medida, a identidade permanece fragmentada pelos múltiplos outros. Nietzsche (1988, v. 3, p. 594) suspeitou que por trás do desejo de conhecimento e de apropriação existe uma vontade "em meio a tudo o que é estranho, inabitual, duvidoso, descobrir algo que não mais nos inquiete".

Percebe-se que o outro foi submetido a uma situação contraditória no pensamento filosófico, pois, na mesma medida em que houve tentativas de reconhecê-lo, esse processo foi negado, por meio de violenta abstração. Ou seja, para afirmar o universal, excluiu-se o estranho, a diferença, o irracional. Tomá-lo em consideração passou a ser um dos desafios da reflexão filosófica contemporânea, que se vê diante dos limites de seus enfoques epistemológicos, ontológicos e éticos.

A hermenêutica filosófica de Hans-Georg Gadamer concebe o outro de uma perspectiva diferente da filosofia da identidade do idealismo especulativo. O filósofo reteve a lição de Nietzsche quanto à desconfiança dos testemunhos da consciência e por isso devemos ficar "à espreita dos encantamentos e embustes da consciência que se acham em toda a crença poderosa" (Nietzsche, 1988, v. 3, p. 627). A consciência, presa à metafísica, tende sempre à apropriação do outro. Gadamer (1993, v. 2, p. 436) faz um giro em direção à hermenêutica moderna que se centra no "diálogo, porque nele a linguagem se forma, amplia e atua". Além disso, o outro e o estranho tiveram um papel decisivo para a hermenêutica (cf. Waldenfels, 1998), especialmente por meio das categorias estranheza e familiaridade, constitutivas da compreensão.

O estranho, na medida em que nos tira do habitual e do familiar, cria as condições para quebrar a unidade inquestionável que nos é dada pelo pertencimento a uma tradição (familiaridade). Se a tradição tem um papel significativo no fenômeno da compreensão, na medida em que contém a historicidade que nos constitui e que é coextensiva à vida que vivemos; a estranheza, por sua vez, atua como distanciamento temporal, gerando a tensão produtiva com a qual se estabelece a própria situação hermenêutica. Nessa tensão entre familiaridade e estranheza se dá a tarefa 
hermenêutica da compreensão que abre um horizonte novo, onde o sujeito se expõe ao outro, é por ele interrogado. Segundo Gadamer, a tradução de textos é exemplar da tensão que ocorre em toda a compreensão:

Nela [na tradução] o estranho se faz próprio, quer dizer, não permanece como estranho, nem se incorpora à própria linguagem mediante a mera acolhida de seu caráter estranho, senão que se fundem os horizontes de passado e presente num constante movimento como que o que constitui a essência da compreensão. (1993, v. 2, p. 436)

Pelo estranhamento surge a oportunidade de diálogo com o outro, que traz consigo a lógica da pergunta e da resposta. Essa dimensão interrogativa não se assemelha a um código a ser decifrado. O outro traz novas perguntas que levam o parceiro a rever sua posição, explicitá-la. O ponto de partida não é o sujeito, mas o diálogo que nos faz submergir em algo com o outro. Este pode nos surpreender e, assim, somos provocados a sair de nossos enclausuramentos, mesmo que não saibamos para onde vamos. Por isso "o que faz que algo seja um diálogo não é o fato de termos experimentado algo novo, mas sim de havermos encontrado, em um outro, algo que não havíamos encontrado ainda em nossa experiência do mundo" (idem, ibid., p. 211). A situação dialógica ultrapassa um mero dar razões de parte a parte; há algo mais, que Gadamer denomina "potencial de alteridade" e que ultrapassa qualquer consenso: "tal é o limite que Hegel não conseguiu atingir", uma vez que concebeu o "conhecimento de si mesmo na alteridade" (ibid., p. 336), resultando na vontade de poder que Nietzsche descobre, com aguçado faro psicológico, em toda a submissão e sacrifício. O empenho de Gadamer é superar o logocentrismo da ontologia grega. A alteridade dáse pela presença de um outro que nos interpela e força a abrir nosso horizonte interpretativo. Por isso a identidade do interlocutor não está absolutamente fixada, mas se desenvolve na conversação, pois "o logos não é um monólogo" e "todo o pensar é um diálogo consigo mesmo e com os outros" (Gadamer, 1998, p. 239). O sentido nasce do encontro do eu com o outro. O giro hermenêutico que o filósofo promove em direção à conversação não retrocede à dialética platônica nem à hegeliana, mas significa um movimento de saída de si mesmo, "pensar com o outro e voltar sobre si mesmo como outro" (Gadamer, 1993, v. 2, p. 369). O diálogo tem, assim, uma força transformadora, pois, quando se realiza efetivamente, algo nos afeta e nos transforma.

Só com o desenvolvimento de uma consciência filosófica, liberta dos constrangimentos metafísicos, que o outro pode surgir num espaço dialógico, para além de um esquema de apropriação. Segundo Waldenfels (1998), contudo, Gadamer não escaparia a isso, pois confia que o estranho possa ser superado, permanecendo preso à órbita de Hegel. Tal crítica expõe os limites daquilo que é apreensível, ou seja, é possível um entendimento do outro sem submetê-lo aos nossos esquemas interpretativos? A ideia de "conceber" o outro já não está presa a nossa estrutura epistemológica? 
Numa relação educativa, o problema aqui posto adquire contornos bem delineados. Uma subjetividade fundamentada no si mesmo, ao ser transposta para a relação pedagógica, traz o risco de submeter o outro. E, nesta mesma direção, cabe ainda perguntar se há justiça nas ações pedagógicas em relação à singularidade do outro. É realmente possível manter uma legitimação moral sem submeter os que se educam a certos ordenamentos simbólicos, normas e mandatos?

Isso nos remeteria para o limite da compreensão, o limite daquilo que não podemos dispor conceitualmente, que não podemos determinar. Segundo Schäfer (2005, p. 204), "respeitar esse limite significa, ao mesmo tempo, também não medir a singularidade do outro com o parâmetro da normalidade da autonomia pura".

Schäfer alerta, ainda, que essa situação gera nova dificuldade: "a mistificação", em que o outro adquire um caráter "sagrado", pois não há parâmetros para saber como se comportar em relação a ele, dada a sua não apreensibilidade. Do outro só temos "vestígios". Se seguíssemos nossos esquemas interpretativos, não faríamos jus à sua singularidade e isso indica que a relação com o outro e o estranho torna-se problemática, pois uma relação pura não é possível. Uma situação assim remete-nos para uma compreensão irrevogável da diferença e exige sensibilidade para esses limites, que só os percebe quem se abre para o horizonte do outro. Nosso modo de conceber a ação pedagógica sempre se mostrou cativo dessa problemática e, talvez, seu aspecto mais evidente esteja na ingenuidade de querer determinar "a realidade" do aluno, querer conhecer para garantir uma ação planejada, efetiva e que produza determinados resultados.

Creio que a proposta de Gadamer deva ser avaliada com prudência, pois ela não sustenta mais nenhuma atitude tirânica do sujeito. $\mathrm{O}$ outro não existe para o próprio reconhecimento de si. Ao contrário, o processo de compreender indica que, apesar de tudo, sempre nos aproximamos uns dos outros. A hermenêtica constitui-se numa possibilidade de relação entre o eu e a alteridade, que supera a exclusão e a apropriação, uma vez que o diálogo só pode existir se houver um outro. Ou seja, o reconhecimento do outro surge no próprio diálogo e a subjetividade constitui-se na intersubjetividade. A radicalidade da questão da linguagem, que atua e se amplia no diálogo, não parte da consciência, pois, de acordo com Gadamer, ele foi alertado por Heidegger dos riscos do logocentrismo, que faz com que a tensão entre autorrenúncia e autorrelação invada a esfera da conversação (cf. Gadamer, 1993, v. 2). Não se trata, portanto, de uma ingênua volta ao outro, enredada ainda na perspectiva hegeliana, mas de retomar a pergunta que Gadamer (op. cit., p. 336-337) apresentou: ${ }^{6}$

(...) como se medeiam reciprocamente a comunidade de sentido que se produz no diálogo com a opacidade do outro, e que é a linguisticidade em última instância, uma ponte ou uma barreira. Uma ponte para comunicar-se um com o outro e construir identidades sobre o rio 
da outreidade, ou uma barreira que limita nossa autoentrega e a priva da possibilidade de nos expressarmos e nos comunicarmos.

Na lucidez dessa pergunta subjaz a questão ética da educação, pois, se conseguirmos produzir um sentido comum sobre o mundo - e esta é uma esperança do programa humanista de Gadamer - e tivermos sensibilidade com o outro, podemos levar adiante uma formação, que abre horizontes. Esses horizontes, nos quais estão presentes a linguagem e a historicidade, constituem-se em fontes inesgotáveis de sentido, que possibilitam uma constante recriação de nós mesmos e do outro. Nessa perspectiva de compreender o outro, a hermenêutica revela seu impulso ético. Considerando, ainda, o ensinamento hermenêutico de que entre filosofia e poesia há uma enigmática aproximação, esta questão ética da relação entre o eu e o outro pode ser adensada com a extraordinária força poética de Octavio Paz, no seu poema Piedra de Sol, escrito em 1953:

\section{(...)}

nunca la vida es nuestra, es de los otros,

la vida no es de nadie, todos somos

la vida - pan de sol para los otros,

los otros todos que nosotros somos -,

soy otro cuando soy, los actos míos

son más míos si son también de todos,

para que pueda ser he de ser otro,

salir de mí, buscarme entre los otros,

los otros que no son si yo no existo,

los otros que me dan plena existencia,

no soy, no hay yo, siempre somos nosotros,

la vida es otra, siempre allá, más lejos,

fuera de ti, de mí, siempre horizonte,

vida que nos desvive y enajena,

que nos inventa un rostro y lo desgasta,

hambre de ser, oh muerte, pan de todos,

Eloísa, Perséfona, María,

muestra tu rostro al fin para que vea

mi cara verdadera, la del otro,

mi cara de nosotros siempre todos.

\section{Notas}

1. Aqui sigo a sugestão de Wils (1993), que oferece uma tipologia das formas de relacionamento entre o estranho e a identidade. 
2. Segundo a interpretação de Dodds, Platão é influenciado pela tradição religiosa-pitagórica, mas também pelo racionalismo grego, o que resulta num ato verdadeiramente criativo, em que o filósofo transpõe as ideias "de um plano da revelação para o plano do argumento racional" (1978, p. 209).

3. Arthur Rimbaud escreve duas cartas, conhecidas como "do vidente", em que aparece essa célebre referência. A primeira delas, Lettre a Georges Izambard, de 13 de maio de 1871, e a segunda, escrita dois dias após a primeira, Lettre a Paul Demeny, de 15 de maio de 1871. Na primeira, o poeta circunscreve a sentença no âmbito do pensamento cartesiano (Penso, logo existo) para afirmar que somos pensados, posicionando-se contra o eu racional e soberano: “Quero ser poeta e trabalho para tornarme vidente: Você não compreenderá nada e eu quase que não saberia explicá-lo. Trata-se de chegar ao desconhecido por meio do desregramento de todos os sentidos. Os sofrimentos são enormes, mas é preciso ser forte, ter nascido poeta, e eu me reconheci poeta. Não é de modo algum culpa minha. É errado dizer: Eu penso; dever-se-ia dizer: sou pensado. - Perdão pelo jogo de palavras. Eu é um outro". Na segunda carta, Rimbaud refere à abertura do eu, em que o outro irrompe para tirar o eu da posição de homogeneidade em que se encontra: "Pois o eu é um outro. Se o cobre acorda o clarim, não é por sua culpa. Isso me é evidente: eu assisto à eclosão do meu pensamento; eu a contemplo; eu a escuto; eu lanço uma flecha: a sinfonia faz seu movimento no abismo, ou salta sobre a cena". Disponível em: <http//www.mag4.Rimbaud/Documents.html>. Acesso em: 30 jul. 2009.

4. Nada do que é humano me é estranho.

5. Fenomenologia do espírito (Phänomenologie des Geistes) é uma obra constituída de oito partes: I. A certeza sensível; II. A percepção; III. Força e entendimento; IV. A verdade da certeza de si mesmo; V. Certeza e verdade da razão; VI. O espírito; VII. A religião; VIII. O saber absoluto. Ao longo do percurso da consciência para tornar-se cada vez mais ela mesma, Hegel convoca diferentes correntes do pensamento para ilustrar os momentos da vida do espírito (a tragicidade dos gregos, o ascetismo da Idade Média, o romantismo alemão, etc.). Para fins deste estudo, nos deteremos no capítulo IV - na dialética do senhor e o escravo -, no qual Hegel expõe o conflito do sujeito entre o desejo de si e o desejo pelo outro, no processo de reconhecimento inerente ao ser humano.

6. Essa pergunta aparece em Texto e interpretação, escrito por Gadamer para o encontro com Jacques Derrida, em Paris, em 1981.

\section{Referências}

ADORNO, T. Negative Dialetik. Gesammelte Schriften. Herausgegeben von Rolf Tiedemann. Darmstadt: Wissenschaftliche Buchsgesellschaft, 1998. v. 6.

ADORNO, T. Ästhetische Teorie. Gesammelte Schriften. Herausgegeben von Rolf Tiedemann. Darmstadt: Wissenschaftliche Buchsgesellschaft, 1998. v. 7.

DODDS, E.R. Plato and the irrational soul. In: Vlastos, G. Plato II: a collection of critical essays. Notre Dame, Indiana: University of Notre Dame, 1978. p. 206-228.

FLICKINGER, H.-G. Senhor e escravo: uma metáfora pedagógica. Revista de Educação, Brasília, DF, v. 29, n. 114, p. 9-20, jan./mar. 2000.

FLICKINGER, H.-G. O fundamento ético da educação contemporânea. Veritas, Porto Alegre, v. 48, n. 2, p. 169-179, jun. 2003.

FREUD, S. O estranho. In: Freud, S. Obras psicológicas completas de Sigmund Freud; edição standard. Rio de Janeiro: Imago, 1988. v. 17, p. 235-269. 
GADAMER, H.-G. Hermeneutik I Wahrheit und Methode: Grundzüge einer philosophischen Hermeneutik. In: Gadamer, H.-G. Gesammelte Werke. Tübingen: Mohr Siebeck, 1990. v. 1.

GADAMER, H.-G. Hermeneutik II Wahrheit und Methode: Ergänzungen, Register. In: Gadamer, H.-G. Gesammelte Werke. Tübingen: Mohr Siebeck, 1993. v. 2.

GADAMER, H.-G. La hermenéutica tras la huella. In: RAmos, A.G. (Ed.). Diálogo y deconstrucción: los limites del encuentro entre Gadamer y Derrida. Madrid: Cuaderno Gris, 1998. p. 231-253.

GUTHRIE, W.K.C. Plato's views on the nature of the soul. In: VLAstos, G. Plato II: a collection of critical essays. Notre Dame, Indiana: University of Notre Dame, 1978. p. 230-243.

HEGEL, G.W.F. Fenomenologia do espírito. Trad. Paulo Menezes. 2. ed. Petrópolis: Vozes; Bragança Paulista: USF, 2003.

HONNETH, A. Luta por reconhecimento: a gramática moral dos conflitos sociais. Trad. Luiz Repa. São Paulo: Editora 34, 2003a.

HONNETH, A. Reconhecimento. In: Canto-Sperber, M. (Org.). Dicionário de ética e filosofia moral. Trad. Paulo Novaes. São Leopoldo: unisinos, 2003b, p. 473-478.

NIETZSCHE, F. Die fröhliche Wissenschaft. In: Ksa. München: Deutscher Taschenbuch; Berlin; New York: de Gruyter, 1988. v. 3.

PAZ, O. Piedra de sol. Disponível em: <http://www.geocities.com/revistaversoados/ webpoemas/webpoemarios/paz-piedradesol>. Acesso em: 20 ago. 2009.

PLATÃO. Górgias. Trad. J. Calongue Ruiz. Madrid: Gredos, 1983. v. 2.

PLATÃO. Fédon. Trad. Carlos García Gual. Madrid: Gredos, 1986. v. 3.

PLATÃO. Fedro. Trad. E. Lledó Íñigo. Madrid: Gredos, 1986. v. 3.

PLATÃO. Parmênides. Trad. Isabel Santa Cruz. Madrid: Gredos, 1998. v. 5.

RICOEUR, P. Si mesmo como outro. Trad. Agustín Neira Calvo. Madrid: Siglo Veintiuno, 1996.

RIMBAUD, A. Lettre de Rimbaud à Georges Izambard (dite "du Voyant"), 13 maio 1871. Disponível em: <http//www.mag4.Rimbaud/Documents.html> Acesso em: 30 jul. 2009.

RIMBAUD, A. Lettre de Rimbaud a Paul Demeny (dite "du Voyant"), 15 maio 1871. Disponível em: <http//www.mag4.Rimbaud/Documents.html> Acesso em: 30 jul. 2009.

SCHÄFER, A. Einführung in die Erziehungsphilosophie. Weinheim und Basel: Beltz, 2005. 
WALDENFELS, B. La pregunta por lo extraño. Logos: Anales del Seminario de Metafisica, Madrid, v. 32, n. 1, p.85-98, 1998.

WILLIAMS, B. Platão: a invenção da filosofia. Trad. Irley Fernandes Franco. São Paulo: UNESP, 2000.

WILS, J.-P. Fremdheit und Identität: Pränormative Mutmassungen. In: WiLs, J.-Pi. Orientierung durch Ethik? Eine Zwischenbilanz. München: Schöning, 1993. p. 131147.

WULF, C. Der Andare. In: Hess, R.; Wulf, C. (Hg.). Grenzgänge: Über den Umgang mit dem Einigen und dem Fremden. Frankfurt; Nova York: Campus Verlag, 1999.

Recebido em agosto de 2009.

Aprovado em novembro de 2010. 